\title{
CARIES PREVALENCE AMONG 5-7 - YEAR-OLD CHILDREN IN NORTHEAST BULGARIA
}

\author{
Evgeni Dimitrov ${ }^{1}$, Milena Georgieva ${ }^{1}$, Radosveta Andreeva ${ }^{1}$, Mariana Dimova- \\ Gabrovska $^{2}$, Hristina Arnautska ${ }^{3}$ \\ 1) Department of Pediatric Dentistry, Faculty of Dental Medicine, Medical \\ University- Varna, Bulgaruia \\ 2) Department of Prosthetic Dental Medicine, Faculty of Dental Medicine, \\ Medical University - Sofia, Bulgaria \\ 3) Department of Orthodontics, Faculty of Dental Medicine, Medical Univesity- \\ Varna, Bulgaria
}

\begin{abstract}
:
The aim of the current epidemiological research is to present the caries prevalence in children and on tooth surfaces in 5-7 - year-olds from Varna. The object of the current epidemiological research is a representative part of 100 5-7 - year-old children, randomly chosen. The unit of observation is temporary and early mixed dentition, primary molars and their occlusal and approximal surfaces. The survey was carried out according to WHO's criteria. For caries risk assessment it is used the ICDAS system, where for a diagnostic limit was chosen $\mathrm{d} 3 \mathrm{mft}$. As a result from the conducted epidemiological research it is concluded that in this age group $93 \%$ of the children have experience with caries and barely $7 \%$ are caries free (dmft/ $\operatorname{DMF}(\mathrm{T}+\mathrm{t})=0)$. The intensity $\mathrm{d}_{1-3 \mathrm{mft}}$ and $\mathrm{D}_{1-3} \mathrm{MF}(\mathrm{T}+\mathrm{t})$ of the caries have an average value of 5,76 $\pm 2,9$. The relative share of the approximal caries of the primary molars on maxilla and mandible is $81,5 \%$ for both. The relative share of the occlusal caries is $19,6 \%$. In the current research, it is not established statistically significant difference $(\mathrm{P}>0,05)$ concerning approximal lesions on first and second primary molar. There is the statistically significant difference $(\mathrm{P}<0,05)$ in the relative share of occlusal caries, which mainly affects the occlusal surface on the second primary molar. The relative share of the children without occlusal caries on primary molar is $60 \%$, while those without approximal caries is barely $18 \%$.
\end{abstract}

Keywords: caries prevalence, distribution of caries among children, epidemiologic research for occlusal and approximal caries

\section{INTRODUCTION:}

Dental caries and its complications are more likely to become a significant medical problem for the children. Nowadays, when the dental health of the children and adolescences is a quite substantial challenge in Bulgaria, is established [1] that a significant part of them have experience with this disease on primary molars with its specific characteristics. The serious complications with inflam- matory and dysfunctional nature, the reflection on the child's common health, the orthodontic problems, the high risk of the future pathology of the oral cavity, imposes the need of very comprehensive and thoroughly research of the carious pathology. These problems also require the usage of complex prophylaxis measures, as well as actively treatment of the affected children.

In the United States of America around 50\% of the 5-9-year-old children have at least one caries or restoration, and this proportion increases to $78 \%$ at 17 -year-olds [2].

In 2004-2005 are clinically examined 349 children in 2-6 years of age in Northwest parts of Canada [3]. The dental caries is a predominant health problem among these children in pre-school age. It is known that 66\% (230/349 children) have experience with the disease and mean 4,8 affected teeth, 2,4 of them remain untreated. Twelve percent (42/349) of the children need urgent dental help.

The proportion of 5-year-olds in England where it is not observed clinically obvious caries is $75,2 \%$ [4]. The rest $24,7 \%$ have one or more carious teeth - diagnostic limit $\mathrm{d} 3 \mathrm{mft}$, as well as teeth restored or extracted due to carious process. The mean value of $\mathrm{d} 3 \mathrm{mft}$ is 0,8 as the index varies from 0,6 to 2,5 .

During the oral status examination of 7-year-olds in Belgium [5] in the period between 1996-2001 depending on the social status of their parents the following values of $\mathrm{dmft}$ and $\mathrm{dmfs}$ are received - children with high socioeconomic status 1,3/2,7 and three times higher values of these indexes in children with low socio-economic stats $3,9 / 9,1$. The frequency of the caries free children is 2,5 times higher among families with high socio-economic status compared with those with low socio-economic status [5].

Another similar epidemiological research in Italy published in 2016 [6], shows that $56,6 \%$ of 5 -year-olds have caries free temporary dentition and the average value of dmft is $1.44 \pm 2.13$.

In Greece [7] during 2012 is published epidemiological research of the caries disease in 1209 children with age of 5 years. For diagnostic limit criteria, d $3 \mathrm{mft}$ is cho- 
sen. Dental caries varies much between the different regions, as its mean value is 1,77 . $64 \%$ of 5-year-olds do not have experience with dentin caries.

According to Prof. Peneva [8] in Bulgaria 6-year old children have an average of 6 deep carious lesions and also four initial. The affected teeth are $34 \%$. More than $80 \%$ of the children have caries at this age $-9 \%$ have caries in their permanent teeth, despite their fresh eruption, and $88 \%$ of the children have caries on the temporary teeth. Almost $50 \%$ of the temporary teeth are affected by caries, and the permanent ones - 30\% [8]. During 2010 in Bulgaria another epidemiologic research for caries prevalence was carried out in 3 age groups. The results show the following: The data of the caries prevalence demonstrate much higher values than the WHO's global aim. The relative share of caries-free children of 5-6 years $(\mathrm{dmft}=0)$ is only $28,87 \%$. With age, this relative share of caries-free children decreases. In all age groups, the values of the indexes are higher in village regions compared to those in cities. The analysis of the data for dmft separated in regions shows dramatic differences: from 2,21 in Pleven region up to 6,66 in Smolyan region. The average value of $\mathrm{dmft}$ index for the whole country is 3,69 [1].

The described data gave us the reason to do a more comprehensive and thorough research regarding the epidemiology of the caries disease on the primary teeth as well as the relation between approximal and occlusal caries on the primary molars.

The aim of the current epidemiological research is to present the caries prevalence in children and on tooth surfaces in 5-7 - year-olds from Varna.

\section{MATERIAL AND METHODS:}

The object of the current epidemiological research is a representative part of 100 5-7 - year-old children, randomly chosen. The unit of observation is temporary and early mixed dentition, primary molars and their occlusal and approximal surfaces. The survey was carried out according to WHO's criteria. For caries assessment ICDAS system is used, as for a diagnostic limit, $\mathrm{d}_{3} \mathrm{mft}$ is chosen. For analysis and data interpretation, received from the epidemiologic research, are used parametric and nonparametric statistic methods. After data revision and determining the main accents an essential research is performed by data process with mathematical-statistic software SPSS v 20.0

\section{RESULTS AND DISCUSSION:}

As a result of the conducted epidemiologic research among 100 children in Varna (31 - 5 years, $39-6$ years and $30-7$ years) it is clear that $93 \%$ of this group are affected by caries. The caries distribution is quite high as the children who are caries free are barely $7 \%(\mathrm{dmft}=0)$ (fig. 1 ). These results are significantly higher compared to those published by other authors $[2,9,10]$. A significant difference is also observed in caries distribution in 5-year-old children in England (75,2\% - caries free, 24,7\% affected by caries) [4]. In Norway caries, free children at 5 years of age are $48 \%-52,5 \%$, while the immigrant caries free chil- dren at the same age are barely 11,4\% [11].

Fig. 1. Individual distribution of caries in 5-7 - yearold children. Children with/without caries.

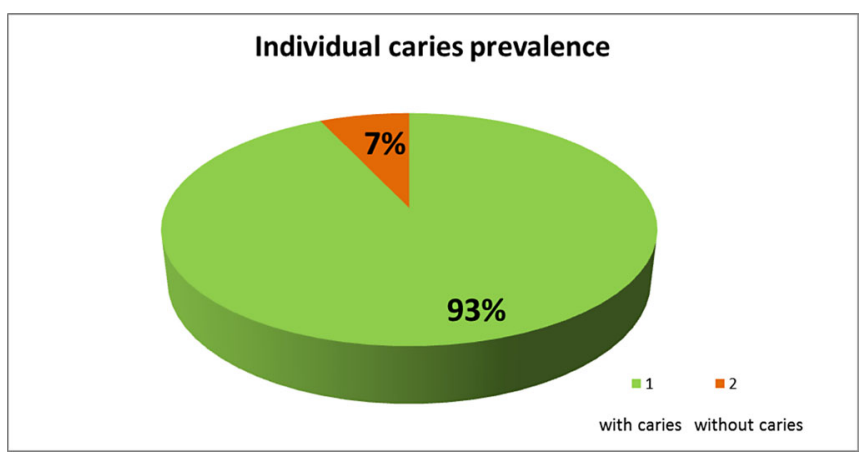

The intensity $-\mathrm{d}_{1-3} \mathrm{mft}$ and $\mathrm{D}_{1-3} \mathrm{MF}(\mathrm{T}+\mathrm{t})$ of the carious process in this age group has an average value of 5,76 $\pm 2,9$. The intensity for 5 years old children is $5,48 \pm 3,32$, for6 - year-olds $-5,31 \pm 2,65$, for 7 - year-olds is $6,5 \pm$ 2,71 (fig. 2). These results are not significantly higher compared to the those reported by Andreeva [9]. She reports $\operatorname{DMF}(\mathrm{T}+\mathrm{t})$ index 4,17 , as for the city regions it is 3,25 and for the village regions - 5,08. The data received from the current research is close to those presented by the National Epidemiological research in Bulgaria in 2010, as well as other local and foreign surveys [2, 4, 10, 12, 13, 14].

Fig. 2. Caries intensity for 5 years old (1), 6 years old (2) and 7 years old (3) children.

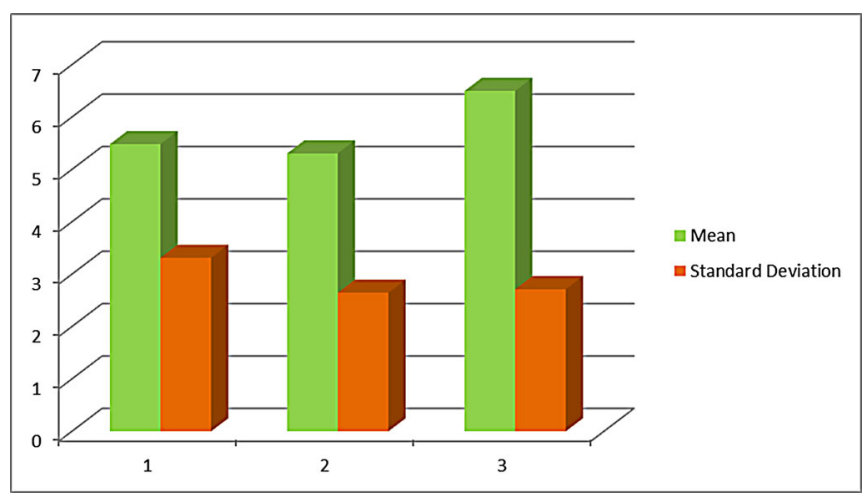

From the examined 100 children at 5-7 years, in the current epidemiological survey is reported, that the relative share of the approximal lesions on primary molars for maxilla and mandible is $81,5 \%$ for both. The relative share of the occlusal caries is $19,6 \%$ (Fig. 3). This fact opposes to other data from the literature concerning caries distribution on primary molars, which report that the most affected surface is the occlusal one of the second primary molar. Some authors declare $52 \%$ distribution of occlusal caries on primary molars $[15,16,17]$. In Norway, $40 \%$ of the children at 5 years have approximal caries and 76,2\% occlusal [11]. Corråa-Faria, Paixào-Gonçalvesetal. [18] have established $47,5 \%$ to $88 \%$ primary molars affected by caries.

In the current survey, it is not established statisti- 
cally significant difference $(\mathrm{P}>0,05)$ in the relative share of approximal caries on first and second primary molar. There is a statistically significant difference $(P<0,05)$ in the relative share of the occlusal carious lesions which affects the second primary molar the most. This is confirmed by other epidemiologic researches which report that the occlusal surface of the second primary molar is more affected by the carious process compared to the one on the first primary molar $[15,16,19,20]$.

Fig. 3. The relative share of the approximal and occlusal caries on primary molars in 5-7 - year-old children.

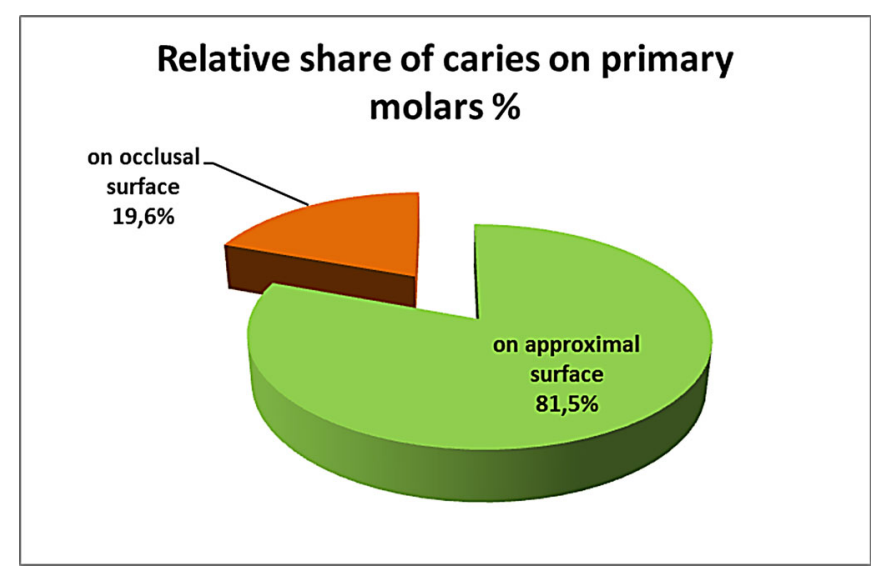

The relative share of the children without occlusal caries on primary molar is $60 \%$ while those without approximal is barely $18 \%$ (fig. 4). These results show the difference with other literature sources which report for $34 \%$ and more approximal caries free children [21, 22, 23]. Some authors prove that $68 \%$ of the children at 6 years have approximal caries on primary molars, while barely $32 \%$ are without approximal caries on primary molar [24].

Fig. 4. The relative share of children without approximal/occlusal caries on primary molars.

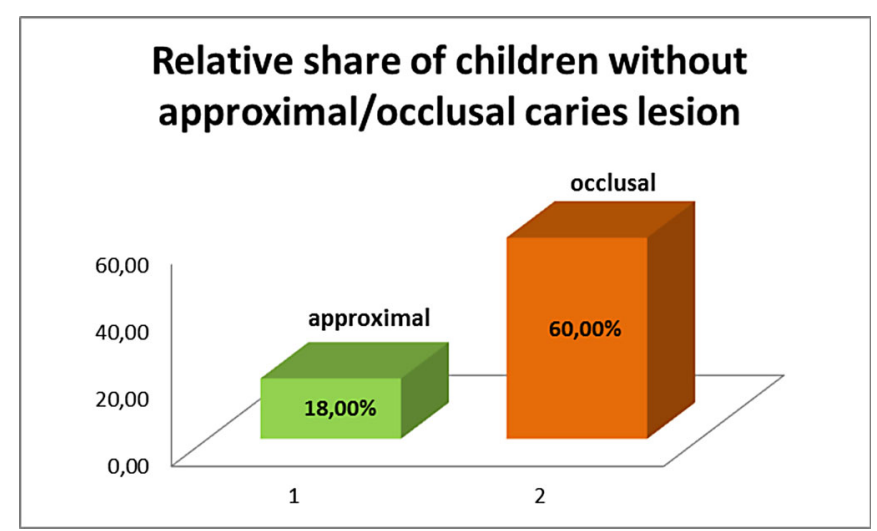

\section{CONCLUSION:}

Asa result from the conducted epidemiological research in this age group $93 \%$ of the children have experience with caries, and barely $7 \%$ are caries free $(\mathrm{dmft} /$ $\operatorname{DMF}(\mathrm{T}+\mathrm{t})=0)$. The intensityd $\mathrm{d}_{1-3} \operatorname{mftandD}_{1-3} \mathrm{MF}(\mathrm{T}+\mathrm{t})$ of the carious lesion has average value of $5,76 \pm 2,9$. The relative share of the approximal caries of the primary molars on maxilla and mandible is $81,5 \%$ for both. The relative share of the occlusal caries is $19,6 \%$. In the current research it is not established statistically significant difference $(\mathrm{P}>0,05)$ concerning the approximal carious lesion on first and second primary molar. There is the statistically significant difference $(\mathrm{P}<0,05)$ in the relative share of occlusal caries, which mainly affects the occlusal surface on the second primary molar. The relative share of the children without occlusal caries on primary molar is $60 \%$, while those without approximal caries is barely $18 \%$.

The received data confirms the high distribution of caries in 5-7 - year-old children, related with the approximal surfaces of the primary molars. There are differences in the distribution and the severity of the approximal and occlusal carious lesions on primary molars. The epidemiological research confirms the importance of current problem related to the prophylaxis and the dental health in childhood age. 


\section{REFERENCES:}

1. National epidemiologic study for the oral health status establishment in three age groups of children in Bulgaria, report, Dec. 2011: 3-5. [in Bulgaran]

2. Bagramian RA, Garcia-Godoy F, Volpe AR. The global increase in dental caries. A pending public health crisis. Am J Dent. 2009 Feb;22(1):3-8. [PubMed]

3. Leake J, Jozzy S, Uswak G. Severe dental caries, impacts and determinants among children 2-6 years of age in Inuvik Region, Northwest Territories, Canada. J Can DentAssoc. 2008 Jul-Aug;74(6):519.[PubMed]

4. Dental Public Health Intelligence Team. Oral health survey of five-year-old children 2015. A report on the prevalence and severity of dental decay. Public Health England. 2016: 8-24.

5. Vanobberge JN, Martens LC, Lesaffre E, Declerck D. Parental occupational status related to dental caries experience in 7-year-old children in Flanders (Belgium). Community Dent Health. 2001 Dec;18(4):256-62. [PubMed]

6. Ferrazzano GF, Sangianantoni $\mathrm{G}$, Cantile T, Ingenito A. Relationship Between Social and Behavioural Factors and Caries Experience in Schoolchildren in Italy. Oral Health Prev Dent. 2016;14(1):55-61 [PubMed]

7. Oulis CJ, Tsinidou K, Vadiakas G, Mamai-Homata E, Polychronopoulou A, Athanasouli T. Caries prevalence of 5, 12 and 15-year-old Greek children: a national path finder survey. Community Dent Health. 2012 Mar; 29(1):29-32.[PubMed]

8. Peneva M. [The way of changing the operative with non-operative preventive treatment of the dental caries.] [Dissertation.] 2008: 45-51. [in
Bulgarian]

9. Andreeva R. [Premature loss of primary teeth in children with early mixed dentition. Needs of space maintainers.] [Dissertation.] 2016: 60-68.

10. Doichinova L. Peneva M. Prevalence of dental caries in hearing impaired children than 5 to 12 years old in Sofia. IJSR. 2015 Jan;4(1):1088-91.

11. Skeie MS, Espelid I, Skaare AB, Gimmestad A. Caries patterns in an urban preschool population in Norway. Eur J Paediatr Dent. 2005 Mar;6(1): 16-22.[PubMed]

12. Damyanova D, Angelova S, Targova-D T, Ivanova K. Temporary Teeth Caries Intensity of Children Aged 4 to 6 Years from the Town Varna, Bulgaria. IOSR-JDMS. 2016 Aug;15(8/ 11):96-99 [CrossRef]

13. De Amorim RG, Figueiredo MJ, Leal SC, Mulder J, Frencken JE. Caries experience in a child population in a deprived area of Brazil, using ICDAS II. Clin Oral Investig. 2012 Apr; 16(2):513-20. [PubMed]

14. Peneva M, Rashkova M, Doichinova L. Age distribution of caries lesions in children's permanent teeth - a basis for the choice of a therapeutic solution. J of IMAB. 2007; 13(2):58-60. [Internet]

15. Bruzda-Zwiech A, Filipinska R, Borowska-Struginska B, Zadzinska E, Wochna-Sobanska M. Caries Experience and Distribution by Tooth Surfaces in Primary Molars in the Preschool Child Population of Lodz, Poland. Oral Health Prev Dent. 2015; 13(6):557-66.[PubMed]

16. Elfrink ME, Veerkamp JS, Kalsbeek H. Caries pattern in primary molars in Dutch 5-year-old children. Eur Arch Paediatr Dent. 2006 Dec; 7(4):236-40. [PubMed]
17. Ferro R, Besostri A, Olivieri A. Caries prevalence and tooth surface distribution in a group of 5-year-old Italian children. Eur Arch Paediatr Dent. 2009 Jan;10(1):33-7. [PubMed]

18. Corrêa-Faria P, PaixãoGonçalves S, Paiva SM, Pordeus IA. Incidence of dental caries in primary dentition and risk factors: a longitudinal study. Braz Oral Res. 2016 May 20;30(1):e59 [CrossRef]

19. Autio-Gold JT, Tomar SL. Prevalence of noncavitated and cavitated carious lesions in 5-year-old headstart school children in Alachua County, Florida. Pediatr Dent. 2005 JanFeb;27(1):54-60.[PubMed]

20. Kuvvetli SS, Cildir, SK, Ergeneli S, Sandalli N. Prevalence of Noncavitated and Cavitated Carious Lesions in a Group of 5-year-old Turkish Children in Kadikoy, Istanbul. $J$ Dent Child (Chic). 2008 May-Aug; 75(2):158-63. [PubMed]

21. Bimstein E, Eidelman E, Klein H, Chosack A. Distribution of Caries in Different Tooth Surfaces in 7-YearOld Children. Caries Res. 1981; 15: 324-30 [CrossRef]

22. Greenwell AL, Johnsen D, DiSantis TA, Gerstenmaier J, Limbert N. Longitudinal evaluation of caries patterns form the primary to the mixed dentition. Pediatr Dent. 1990 SepOct;12(5):278-82.[PubMed]

23. Sundberg H. Changes in the Prevalence of Caries in Children and Adolescents in Sweden 1985-1994. Eur J Oral Sci. 1996 Aug;104(4 (Pt 2)): 470-6. [PubMed]

24. Douglass JM, Wei Y, Zhang BX, Tinanoff N. Caries prevalence and patterns in 3-6-year-old Beijing children. Community Dent Oral Epidemiol. 1995 Dec;23(6):340-3. [PubMed]

Please cite this article as: Dimitrov E, Georgieva M, Andreeva R, Dimova-Gabrovska M, Arnautska H. Caries prevalence among 5-7 - year-old children in Northeast Bulgaria. J of IMAB. 2017 Jul-Sep;23(3):1633-1636.

DOI: https://doi.org/10.5272/jimab.2017233.1633

Address for correspondence:

Dr. Evgeni Dimitrov,

Department of Pediatric Dentistry, Faculty of Dental Medicine - Varna

19, prof. VankoVankov str., $1^{\text {st }}$ floor, ap. 1.

e-mail: eugene_d@abv.bg 